\title{
Weldable and Reprocessable Biomimetic Polymer Networks Based on a Hydrogen Bonding and Dynamic Covalent Thiourea Motif
}

Dong Soo Lee, $\uparrow^{\text {ab }}$ Yong-Seok Choi, $\uparrow^{\mathrm{c}}$ Jae Hyuk Hwang, ${ }^{\text {ad }}$ Jin-Hyeong Lee, ${ }^{\mathrm{e}}$ Woohwa Lee, ${ }^{\mathrm{a}}$ Suk-kyun Ahn, e Sungmin Park, ${ }^{a}$ Jung-Hyun Lee, ${ }^{\mathrm{b}}$ Yong Seok Kim, ${ }^{\text {*af }}$ and Dong-Gyun $\mathrm{Kim}^{* a f}$

aAdvanced Materials Division, Korea Research Institute of Chemical Technology, 141 Gajeong-ro, Yuseong-gu, Daejeon 34114, Republic of Korea.

bDepartment of Chemical and Biological Engineering, Korea University, 145 Anam-ro, Seongbuk-gu, Seoul o2841, Republic of Korea.

'Composite Materials Application Research Center, Korea Institute of Science and Technology, 92 Chudong-ro, Bongdong-eup, Wanju-gun, Jeonbuk 55324, Republic of Korea.

dSchool of Chemical and Biological Engineering and Institute of Chemical Processes, Seoul National University, 599 Gwanak-ro, Gwanak-gu, Seoul o8826, Republic of Korea.

eDepartment of Polymer Science and Engineering, Pusan National University, 2 Busandaehag-ro, 63 Beon-gil, Geumjeong-gu, Busan 46241, Republic of Korea.

fAdvanced Materials and Chemical Engineering, KRICT School, University of Science and Technology, 217 Gajeongro, Yuseong-gu, Daejeon 34114, Republic of Korea.

*Corresponding author: D.-G. Kim (E-mail: dgkim@krict.re.kr)

Y.S.Kim (E-mail:yongskim@krict.re.kr)

†These authors contributed equally to this work.

\section{$\underline{\text { Table of Contents }}$}

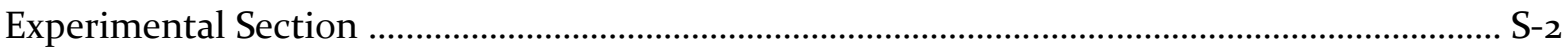

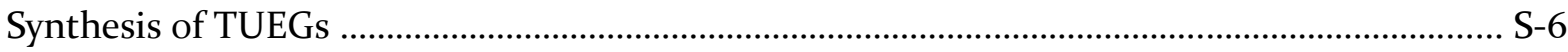

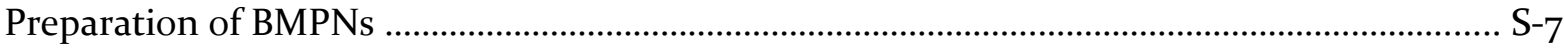

Thermomechanical Characterization of BMPNs .......................................................................... S-9

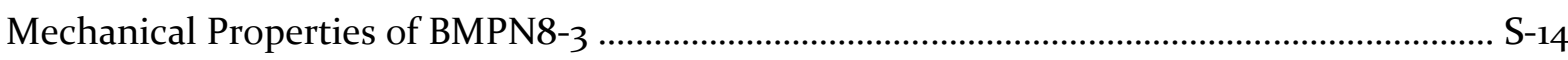

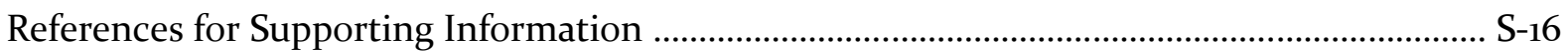




\section{Experimental Section}

\section{$\underline{\text { Materials }}$}

1,1'-Thiocarbonyldiimidazole (TCDI, tech. 90\%, Alfa Aesar), 1,2-bis(2-aminoethoxy)ethane (EGDA, 98\%, Sigma-Aldrich), triglycidyl isocyanurate (TGIC, Sigma-Aldrich), 1,5,7-Triazabicyclo[4.4.o]dec-5ene (TBD, 98\%, Sigma-Aldrich), 1-heptyl-3-phenylthiourea (HPT, Trans World Chemicals), dimethyl suloxide- $d_{6}$ (DMSO- $d_{6}, 99.5$ atom \% D, Sigma-Aldrich), and $N, N$-dimethylformamide (DMF, anhydrous, 99.8\%, Sigma-Aldrich) were used as received. All other reagents and solvents were used as received from standard vendors.

\section{Synthesis of Poly(ether-thiourea) with Triethylene Glycol as a Spacer (TUEG)}

Poly(ether-thiourea)s with triethylene glycol as a spacer are designated as TUEG\#, where \# indicates the average degree of polymerization (DP) as estimated by ${ }^{1} \mathrm{H}$ NMR end group analysis. TUEGs were synthesized similarly with the route described elsewhere (Figure $\left.\mathrm{S}_{1}\right) \cdot{ }^{\left[\mathrm{S}_{1}, 2\right]}$ Preparation procedure was conducted under a nitrogen atmosphere in a glove box $\left(<0.1 \mathrm{ppm}\right.$ of $\mathrm{H}_{2} \mathrm{O}$ and $\left.\mathrm{O}_{2}\right)$. For the synthesis of TUEG7, EGDA (6.2 g, $42 \mathrm{mmol}$ ) and DMF (17 mL) were placed into a $100 \mathrm{~mL}$ round-bottomed flask with a magnetic stirring bar, and TCDI $(5.0 \mathrm{~g}, 28 \mathrm{mmol})$ was added into the flask under stirring. The reaction flask sealed with stopper was transferred to a thermostatted oil bath at $25{ }^{\circ} \mathrm{C}$ outside the glove box. After stirred for $24 \mathrm{~h}$, the solution was diluted by chloroform $(15 \mathrm{~mL})$ and precipitated into an excess of ether $(800 \mathrm{~mL})$. The dissolution-precipitation procedure was repeated three times. The resulting precipitate was subsequently dried under vacuum at $120{ }^{\circ} \mathrm{C}$ overnight, yielding a light brownish solid (5.o g, 81\%). TUEG18 was also prepared using the same procedure, but different ratio of the TCDI and EGDA monomer charge ([TCDI] : [EGDA] = $1: 1.055)$ was used. ${ }^{1} \mathrm{H}$ NMR of TUEG7 (40o MHz, DMSO- $d_{6}$, $\delta / \mathrm{ppm}$, tetramethylsilane (TMS) ref) (Figure $\mathrm{S} 2$ ): 7.54 (br, $\mathrm{C}(\mathrm{S}) \mathrm{NH}$ ), 3.60-3.20 (br, $\mathrm{CH}_{2} \mathrm{O}, \mathrm{C}(\mathrm{S}) \mathrm{NHCH}_{2}$ ), $2.68\left(\mathrm{t}, \mathrm{CH}_{2} \mathrm{NH}_{2}\right)$. The DP was determined from the intensity ratio between the peaks at $7.54(\mathrm{br}$, $\mathrm{C}(\mathrm{S}) \mathrm{NH})$ and $2.68\left(\mathrm{t}, \mathrm{CH}_{2} \mathrm{NH}_{2}\right) \mathrm{ppm}$.

\section{Preparation of Biomimetic Polymer Networks (BMPNs) Based on TUEG, TGIC, and TBD}

Cross-linked TUEG-TGIC films with TBD catalyst are designated as BMPN\#- $x$, where \# and $x$ indicate the weight percentage (wt\%) of TGIC, and the molar percentage (mol\%) of TBD to the thiourea moieties, in the film, respectively. The BMPNs without TBD catalyst are simply designated as BMPN\#. The following procedure was applied for the preparation of BMPN8-3. TUEG18 (o.70 g, o.2 mmol), TGIC ( $0.059 \mathrm{~g}, 0.2 \mathrm{mmol})$, and TBD (0.015 g, $0.11 \mathrm{mmol})$ in DMF $(3.5 \mathrm{~mL})$ were cast onto a Teflon plate $(7 \times 3$ $\mathrm{cm}^{2}$ ), followed by drying on a hot plate at $50{ }^{\circ} \mathrm{C}$ overnight. After subsequently dried at $80{ }^{\circ} \mathrm{C}$ under 
vacuum for $1 \mathrm{~h}$, the resultant film on a Teflon plate was cured at $120^{\circ} \mathrm{C}$ for $2 \mathrm{~h}$ and postcured at $15 \mathrm{O}^{\circ} \mathrm{C}$ for $2 \mathrm{~h}$ under vacuum. Other BMPN8s were prepared using the same procedure, except the use of $\mathrm{o}, 1$, and $5 \mathrm{~mol} \%$ of TBD feed ratios to the thiourea moieties for BMPN8, BMPN8-1, and BMPN8-5, respectively. The molar feed ratio of amine end group of TUEG to epoxy group of TGIC ([amine] : [epoxy]) was fixed at 1:1.5 for all the films, this is for the complete reaction of the primary amine and epoxy groups without any unreacted, residual primary amine end-groups or epoxy functional groups. ${ }^{\left[\mathrm{S}_{2}-\right.}$ ${ }_{4]}$ BMPN21 from $79 \mathrm{wt} \%$ of TUEG 7 and $21 \mathrm{wt} \%$ of TGIC cross-linker (the molar feed ratio of amine end group of TUEG to epoxy group of TGIC ([amine] : [epoxy]) =1:2) was also prepared for comparison purposes using the same procedure. To prepare reprocessed BMPN films, broken and cut pieces were placed into a mold $(40 \mathrm{~mm}(\mathrm{~L}) \times 40 \mathrm{~mm}(\mathrm{~W}) \times 0.4 \mathrm{~mm}(\mathrm{~T})$ ), made of Teflon sheets and stainless steel spacer, and pressed under a pressure of $10 \mathrm{MPa}$ at $140^{\circ} \mathrm{C}$ for $2 \mathrm{~h}$. The thickness of the BMPNs was around $400 \mu \mathrm{m}$. All the films were additionally dried at $50^{\circ} \mathrm{C}$ under vacuum for $24 \mathrm{~h}$ before analyses.

\section{Exchange Reaction of 1-Heptyl-3-phenylthiourea (HPT)}

Under a nitrogen atmosphere in a glove box (<0.1 ppm of $\mathrm{H}_{2} \mathrm{O}$ and $\mathrm{O}_{2}$ ), HPT (o.376 g, $\left.1.5 \mathrm{mmol}\right)$, TBD (o.o1g, o.075mmol), and DMSO- $d_{6}(3 \mathrm{ml})$ were placed into a $100 \mathrm{~mL}$ round-bottomed flask with a magnetic stirring bar. Once clearly dissolved solution was obtained, a small aliquot of the initial mixture was taken for ${ }^{1} \mathrm{H}$ nuclear magnetic resonance ( ${ }^{1} \mathrm{H}$ NMR) analysis. The reaction flask sealed with stopper was transferred to a thermostatted oil bath at $120{ }^{\circ} \mathrm{C}$ outside the glove box and stirred. Aliquots were taken and quenched by rapid cooling in an ice bath at various times to monitor the exchange reaction of HPT as a function of time. For the ${ }^{1} \mathrm{H}$ NMR analysis, $\approx 0.1 \mathrm{~mL}$ of each aliquot was diluted using DMSO- $d_{6}(0.4 \mathrm{~mL})$. Exchange reactions of HPT under different conditions (e.g., at different temperatures and without catalyst) were also performed and monitored using the same procedure.

\section{Instrumentation and Characterization Techniques}

${ }^{1} \mathrm{H}$ NMR spectra of TUEGs and 1-heptyl-3-phenylthiourea (HPT) were recorded on a Bruker Ascend $400 \mathrm{MHz}$ using DMSO- $d_{6}$ as solvent. Number-average molecular weights $\left(M_{\mathrm{n}}\right)$ and molecular weight dispersities $(\nexists)$ of TUEGs were determined by gel permeation chromatography (GPC) in DMF (with o.o1M LiBr), using a YL9112 Isocratic pump, a $30 \mathrm{~cm}$ Shodex KF-805L column, and a YL9170 differential refractive index (RI) detector operating at $40{ }^{\circ} \mathrm{C}$. The GPC-RI elution time data were calibrated with narrow-distribution polystyrene standards. Fourier transform infrared (FT-IR) spectra were recorded on an Agilent 4100 Exoscan FTIR spectrometer using attenuated total reflectance (ATR) equipment. Realtime FT-IR spectra of BMPN8-3 were recorded on a Jasco FT/IR-46oo spectrometer under transmission mode using a temperature controlled sample holder. Solvent extraction experiment was performed by placing a small piece (ca. $20 \mathrm{mg}$ ) of BMPN films into a $20 \mathrm{~mL}$ vial filled with DMF. After stored in an 
oven at $25^{\circ} \mathrm{C}$ for $48 \mathrm{~h}$, the film was recovered and dried at $120^{\circ} \mathrm{C}$ under vacuum for $18 \mathrm{~h}$. Gel fraction $\left(f_{\mathrm{g}}\right)$ was calculated as

$$
f_{\mathrm{g}}=W_{\mathrm{a}} / W_{\mathrm{d}}
$$

where $W_{\mathrm{d}}$ and $W_{\mathrm{a}}$ are the weights of dried film before and after the DMF solvent extraction. The thermal stability of BMPNs was investigated by thermal gravimetric analysis (TGA) using a TA Instruments TGA Q50oo under a nitrogen atmosphere. The samples were first heated to $130{ }^{\circ} \mathrm{C}$ and maintained at $130{ }^{\circ} \mathrm{C}$ for $10 \mathrm{~min}$ in order to evaporate residual water, and then heated to $650{ }^{\circ} \mathrm{C}$ at a heating rate of $10^{\circ} \mathrm{C} \mathrm{min}^{-1}$. Differential scanning calorimetry (DSC) was run using a TA Instruments DSC Q10oo under a nitrogen atmosphere. Samples with a typical mass of 5-10 mg were encapsulated in sealed aluminum pans. They were first heated from $25^{\circ} \mathrm{C}$ to $180{ }^{\circ} \mathrm{C}$ and then cooled down to $-50{ }^{\circ} \mathrm{C}$, which were followed by second heating at a constant rate of $10{ }^{\circ} \mathrm{C} \mathrm{min}^{-1}$. Dynamic mechanical analysis (DMA) was performed on a TA Instruments DMA Q8oo with attached cryo accessory using rectangularshaped BMPN films (ca. $30 \mathrm{~mm}(\mathrm{~L}) \times 5 \mathrm{~mm}(\mathrm{~W}) \times 0.4 \mathrm{~mm}(\mathrm{~T})$ ). DMA was conducted in the film tension mode with a $1 \mathrm{~Hz}$ frequency, $0.1 \%$ strain, and $0.1 \mathrm{~N}$ axial force. The specimens were first cooled down from room temperature to $-50^{\circ} \mathrm{C}$ and then heated to $100{ }^{\circ} \mathrm{C}$ at a constant rate of $5^{\circ} \mathrm{C} \mathrm{min}^{-1}$ in a nitrogen atmosphere. Cross-linking density $\left(v_{\mathrm{e}}\right)$ of BMPNs was calculated as

$$
v_{\mathrm{e}}=E^{\prime} / 3 R T
$$

where $E^{\prime}, R$, and $T$ are the storage modulus, universal gas constant, and absolute temperature in the rubbery region, respectively. Quantitative shape memory behavior of BMPN8-3 film (ca. $30 \mathrm{~mm}(\mathrm{~L}) \times 5$ $\mathrm{mm}(\mathrm{W}) \times 0.4 \mathrm{~mm}(\mathrm{~T}))$ was evaluated by the same TA Instruments DMA Q80o with attached cryo accessory under controlled force mode. The sample was first heated from $25^{\circ} \mathrm{C}$ to $60{ }^{\circ} \mathrm{C}$ at a constant rate of $5{ }^{\circ} \mathrm{C} \mathrm{min}{ }^{-1}$ and maintained at $60^{\circ} \mathrm{C}$ for $10 \mathrm{~min}$. The sample was subsequently stretched under a load of 0.15 Mpa for $3 \mathrm{~min}$, followed by cooling to ${ }^{\circ}{ }^{\circ} \mathrm{C}$ at a rate of $5^{\circ} \mathrm{C} \mathrm{min}^{-1}$ under the load (sample length $\left.=\varepsilon_{\text {load }}\right)$ to fix temporary shape. After unloading, the sample maintained the temporary shape with length of $\varepsilon_{\text {unload. }}$. Shape recovery process was then triggered by heating the sample back to $60{ }^{\circ} \mathrm{C}$ at a rate of $5{ }^{\circ} \mathrm{C} \mathrm{min}^{-1}$, which decreased the sample length to $\varepsilon_{\text {rec }}$. Consecutive shape memory cycles were investigated by repeating the above shape memory cycle. Shape fixity ratio $\left(R_{\mathrm{f}}\right)$ and shape recovery ratio $\left(R_{\mathrm{r}}\right)$ were calculated as

$$
\begin{array}{r}
R_{\mathrm{f}}=\left(\varepsilon_{\text {unload }} / \varepsilon_{\text {load }}\right) \times 100 \% \\
R_{\mathrm{r}}=\left[\left(\varepsilon_{\text {unload }}-\varepsilon_{\text {rec }}\right) / \varepsilon_{\text {unload }}\right] \times 100 \%
\end{array}
$$

Shape memory behavior of BMPN8-3 was also confirmed qualitatively; the BMPN8-3 film was deformed to a temporary shape at $50{ }^{\circ} \mathrm{C}$ in an oven and then cooled to ${ }^{\circ}{ }^{\circ} \mathrm{C}$ in a refrigerator to fix the 
temporary shape, which was subsequently placed in an oven at $50{ }^{\circ} \mathrm{C}$ to recover the permanent shape. Stress relaxation behaviors of BMPNs were analyzed by the same TA Instruments DMA Q8oo under stress relaxation mode. The samples were allowed to equilibrate at specified temperature $\left(120-180{ }^{\circ} \mathrm{C}\right)$ for $5 \mathrm{~min}$, after which each sample was subjected to an instantaneous $5 \%$ strain. The stress relaxation was monitored, while maintaining the constant strain (5\%), until the stress relaxation modulus had relaxed to at least $37 \%(1 / \mathrm{e})$ of its initial value. Based on the thermally distinct plasticity and elasticity of BMPN8-3, combined elasticity/plasticity cycling was performed by repeatedly switching the experimental modes (i.e., controlled stress and stress relaxation modes for elasticity and plasticity cycles, respectively) without unloading the sample at each cycle. Uniaxial tensile testing was carried out on an Instron $\mathrm{LR}_{5} \mathrm{~K}$ universal testing machine (UTM, Lloyd Instruments) at a strain rate of $0.011 \mathrm{~s}^{-1}(10 \mathrm{~mm}$ $\mathrm{min}^{-1}$ ) unless otherwise noted. Rectangular shaped tensile bars (ca. $40 \mathrm{~mm}(\mathrm{~L}) \times 5 \mathrm{~mm}(\mathrm{~W}) \times 0.4 \mathrm{~mm}$ $(\mathrm{T})$, gauge length $=15 \mathrm{~mm}$ ) were stamped out from the films using a cutting die. For the lap-shear test, two pieces of BMPN8-3 films (ca. $20 \mathrm{~mm}(\mathrm{~L}) \times 5 \mathrm{~mm}(\mathrm{~W}) \times 0.4 \mathrm{~mm}(\mathrm{~T})$ ) were overlapped with an area of $5 \times 5 \mathrm{~mm}^{2}$ and pressed within two Teflon sheets by external force (the space of two Teflon sheets is 720 $\mu \mathrm{m}$ ), then they were thermally treated in a vacuum oven at $160{ }^{\circ} \mathrm{C}$ for $2 \mathrm{~h}$ (Figure Siza). Tensile mechanical properties of the thermally welded samples were also evaluated by the Instron $\mathrm{LR}_{5} \mathrm{~K}$ UTM applying the same gauge length of $15 \mathrm{~mm}$. At least three different samples were prepared from each film and tested in the UTM. Cyclic tensile testing was performed on the same UTM using the rectangular shaped BMPN8-3 films at a strain rate of $0.011 \mathrm{~s}^{-1}\left(10 \mathrm{~mm} \mathrm{~min}^{-1}\right)$. The samples in between cyclic tests were stored in a vacuum oven at $25^{\circ} \mathrm{C}$ to avoid possible water uptake from the air during the recovery time. All the tensile tests were performed at room temperature and humidity $\left(25 \pm 1{ }^{\circ} \mathrm{C}, \mathrm{RH} 45 \pm 8 \%\right.$ in air), unless otherwise noted. 


\section{Synthesis of TUEGs}

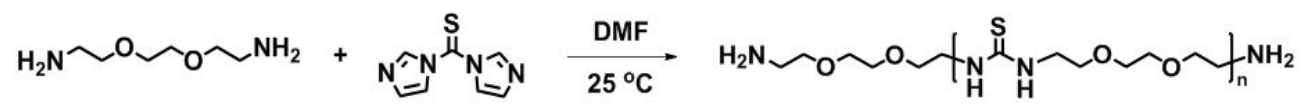

Figure S1. Synthesis of TUEG.

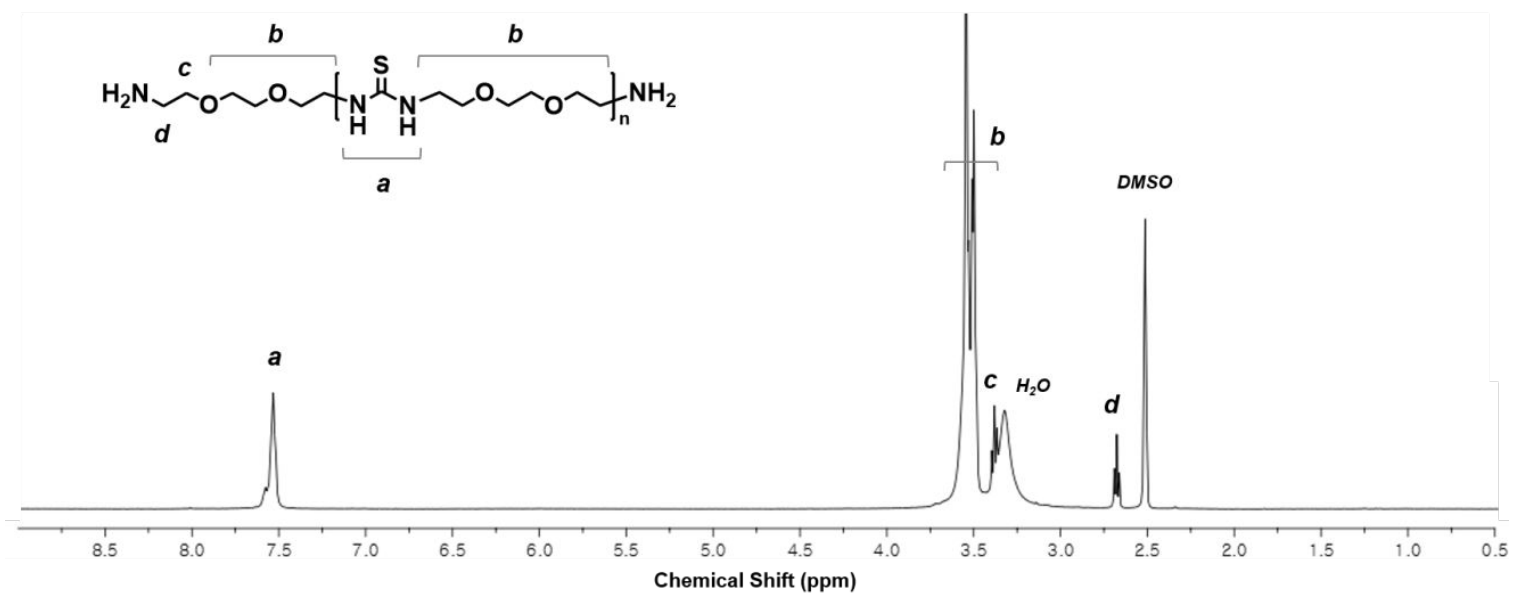

Figure S2. ${ }^{1} \mathrm{H}$ NMR spectrum of TUEG7. 


\section{Preparation of BMPNs}

a

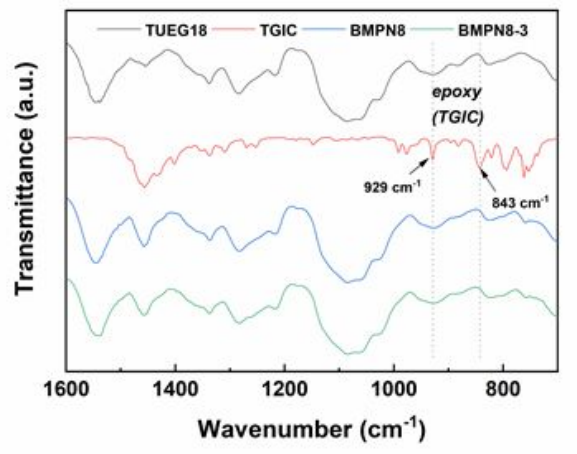

b

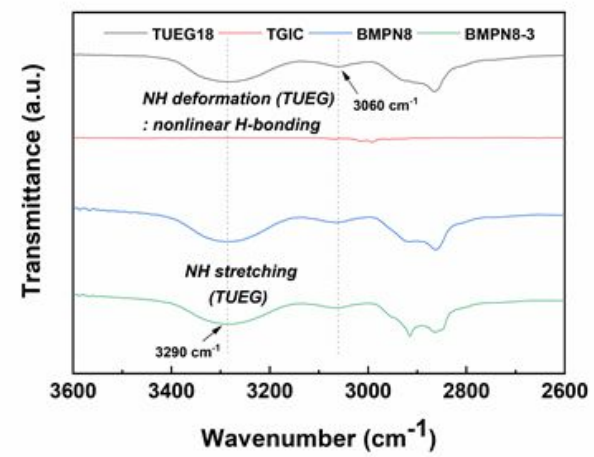

Figure S3. FT-IR spectra of TUEG18, TGIC, BMPN8, and BMPN8-3 in the wavenumber range of (a) $1600-700 \mathrm{~cm}^{-1}$ and (b) $3600-2600 \mathrm{~cm}^{-1}$.

Table S1. Composition, gel fraction, cross-linking density of BMPN8 and BMPN21

\begin{tabular}{llll}
\hline Sample (without TBD) & $W_{\mathrm{TGIC}^{a}}$ & $f_{\mathrm{g}}^{b}$ & $v_{\mathrm{e}}{ }^{\mathrm{c}}\left(\mathrm{mol} \mathrm{m}^{-3}\right)$ \\
\hline BMPN8 $^{d}$ & 0.08 & 0.78 & 179 \\
BMPN21 $^{e}$ & 0.21 & 0.95 & 1,660 \\
\hline
\end{tabular}

${ }^{a}$ Weight fraction of TGIC in the BMPNs. ${ }^{b}$ Gel fraction, obtained by $f_{\mathrm{g}}=W_{\mathrm{a}} / W_{\mathrm{d}}$, where $W_{\mathrm{d}}$ and $W_{\mathrm{a}}$ are the weights of dried film before and after N,N-dimethylformamide (DMF) solvent extraction. ${ }^{c}$ Crosslinking density, calculated by $v_{\mathrm{e}}=E^{\prime} /{ }_{3} R T$, where $E^{\prime}, R$, and $T$ are the storage modulus, universal gas constant, and absolute temperature in the rubbery region (Figure S6), respectively. ${ }^{d}$ Prepared using an amine to epoxy molar feed ratio ([amine end group of TUEG $\left.\left(M_{\mathrm{n}}=3,500 \mathrm{~g} \mathrm{~mol}^{-1}\right)\right]$ : [epoxy group of TGIC]) of $1: 1.5 \cdot{ }^{e}$ Prepared using an amine to epoxy molar feed ratio ([amine end group of TUEG $\left(M_{\mathrm{n}}=\right.$ $1,500 \mathrm{~g} \mathrm{~mol}^{-1}$ )] : [epoxy group of TGIC]) of $1: 2$.

Table S2. Gel fraction and cross-linking density of BMPN8 with different TBD contents

\begin{tabular}{lccc}
\hline Sample $^{a}$ & TBD Content $(\mathrm{mol} \%)$ & $f_{\mathrm{g}}^{b}$ & $v_{\mathrm{e}}^{c}\left(\mathrm{~mol} \mathrm{~m}^{-3}\right)$ \\
\hline BMPN8-1 & 1 & 0.77 & 140 \\
BMPN8-3 & 3 & 0.71 & 88 \\
BMPN8-5 & 5 & 0.68 & 44 \\
\hline
\end{tabular}

a Designated as BMPN8-\#, where the \# indicates the molar percentage (mol\%) of TBD to the thiourea moieties in the BMPN8. ${ }^{b}$ Gel fraction, obtained by $f_{\mathrm{g}}=W_{\mathrm{a}} / W_{\mathrm{d}}$, where $W_{\mathrm{d}}$ and $W_{\mathrm{a}}$ are the weights of dried film before and after $\mathrm{N}, \mathrm{N}$-dimethylformamide (DMF) solvent extraction. ${ }^{c}$ Cross-linking density, calculated by $v_{\mathrm{e}}=E^{\prime} /{ }_{3} R T$, where $E^{\prime}, R$, and $T$ are the storage modulus, universal gas constant, and absolute temperature in the rubbery region (Figure $\mathrm{S} 8$ ), respectively. 
a

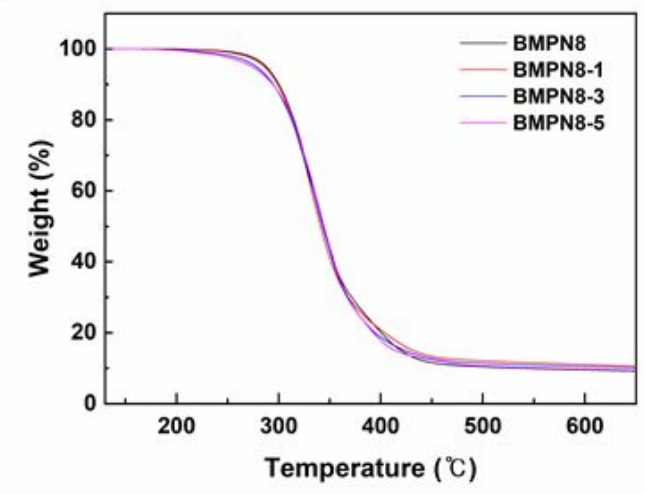

b

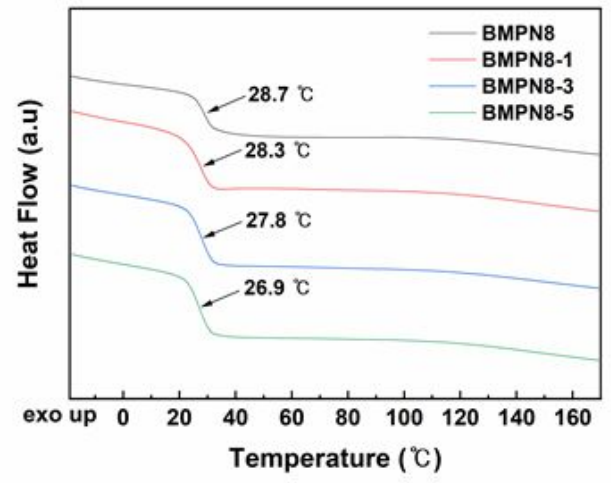

Figure S4 $_{4}$ (a) TGA curves and (b) DSC thermograms of BMPN8s. 


\section{Thermomechanical Characterization of BMPNs}

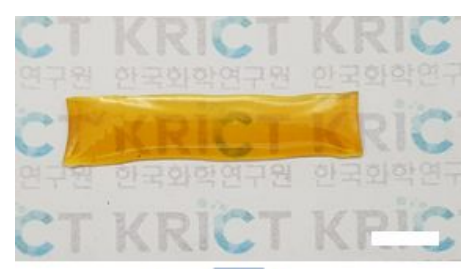

\section{Twisting}

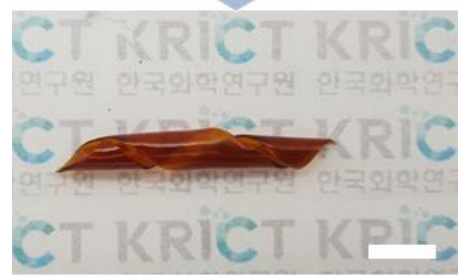

\section{Bending}

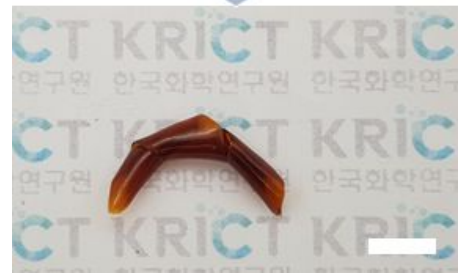

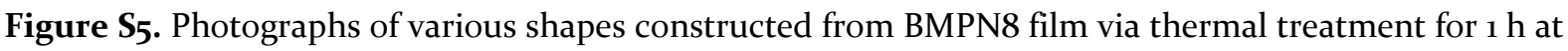
$140{ }^{\circ} \mathrm{C}$ (scale bar $=1.5 \mathrm{~cm}$ ).

a

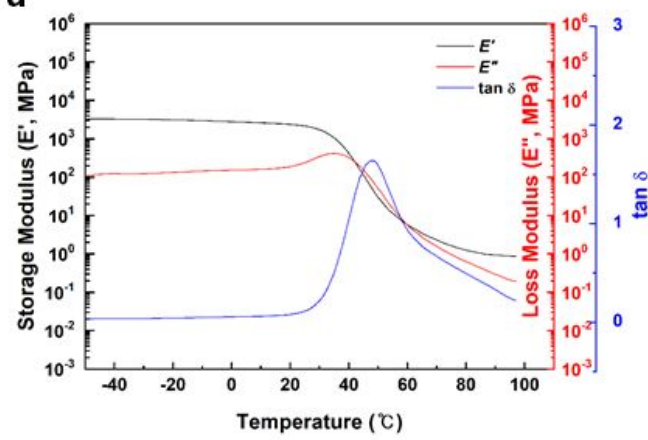

b

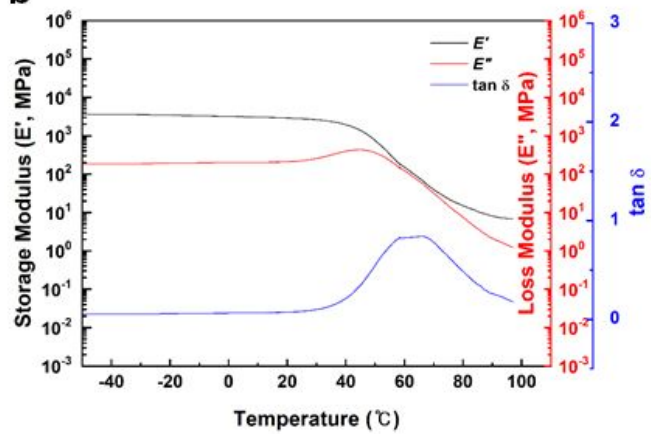

Figure S6. DMA curves of (a) BMPN8 and (b) BMPN21 at a constant frequency of $1 \mathrm{~Hz}$ and a heating rate of $5{ }^{\circ} \mathrm{C} \mathrm{min}^{-1}$. 
a

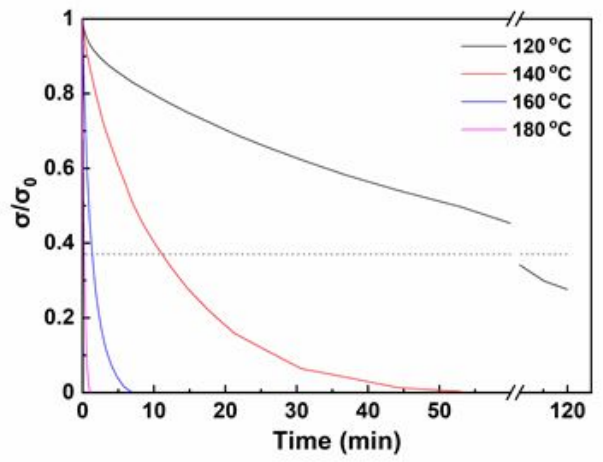

b

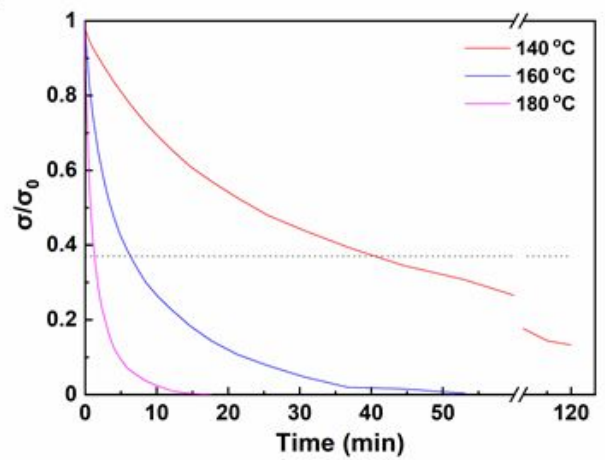

Figure S7. Normalized stress relaxation behaviors of (a) BMPN8 and (b) BMPN21.
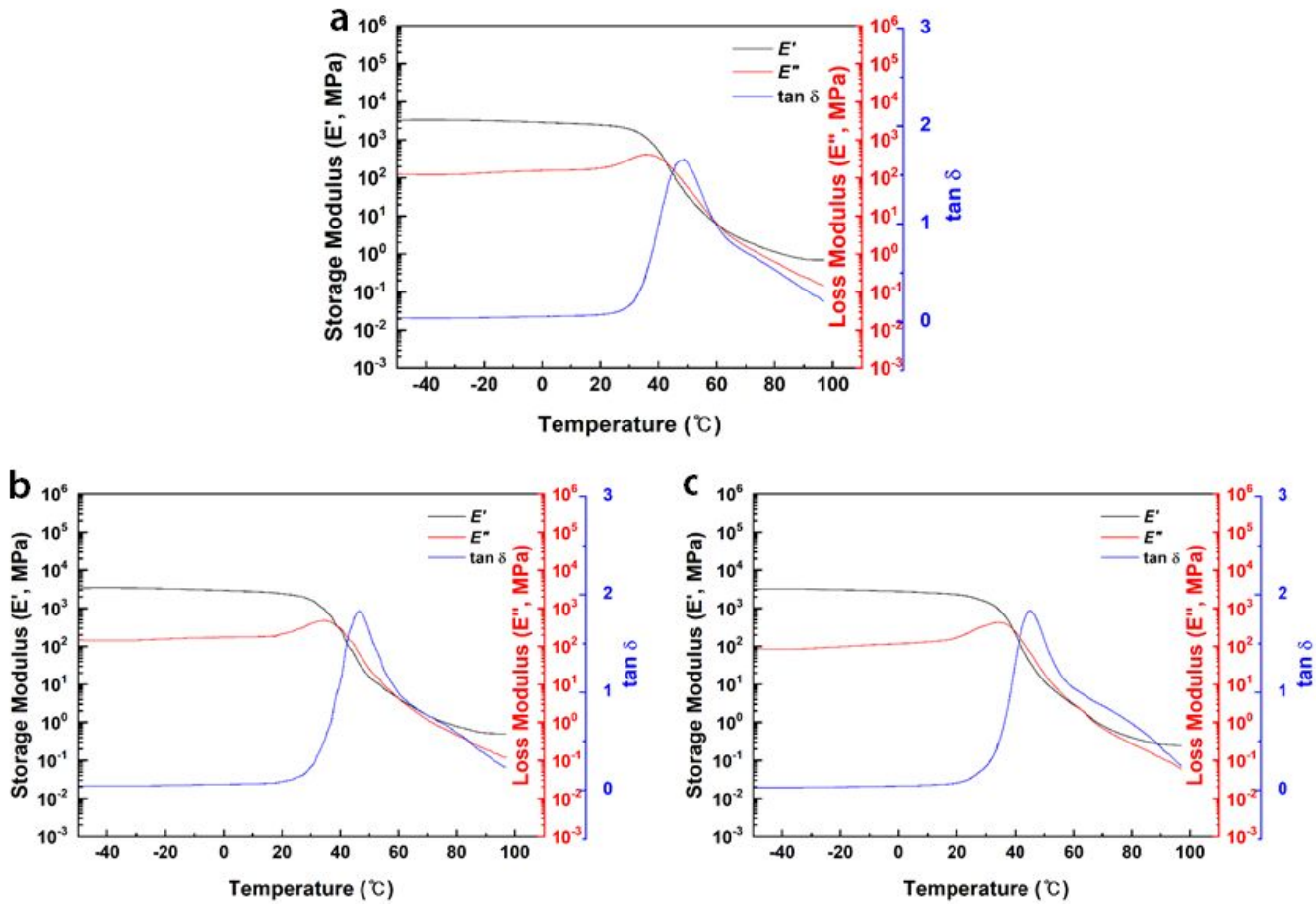

Figure S8. DMA curves of BMPN8 with (a) 1, (b) 3, and (c) 5 mol \% of TBD at a constant frequency of 1 $\mathrm{Hz}$ and a heating rate of $5^{\circ} \mathrm{C} \mathrm{min}^{-1}$. 
a

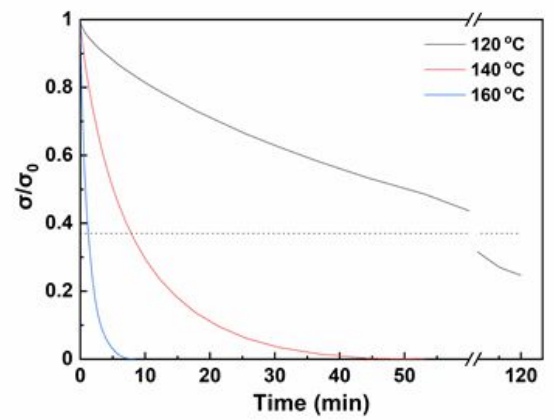

b

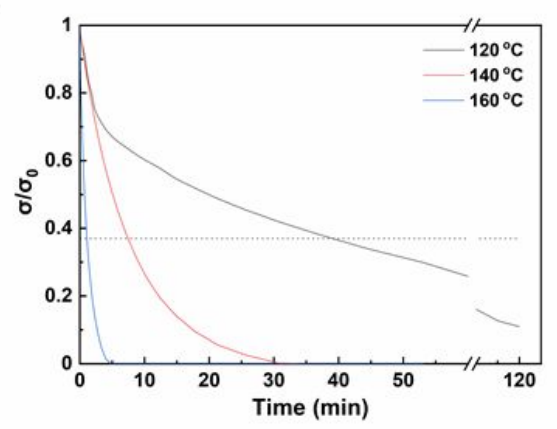

C

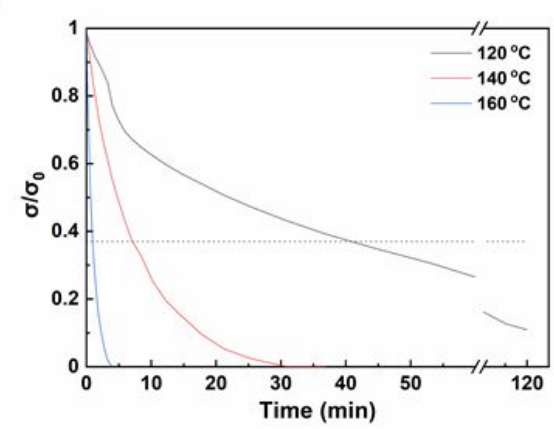

Figure S9. Normalized stress relaxation of BMPN8 with (a) 1, (b) 3, and (c) 5 mol \% of TBD at different temperatures. The dashed line indicates $\sigma / \sigma_{0}=\mathrm{e}^{-1}(\approx 37 \%$ of the initial stress).

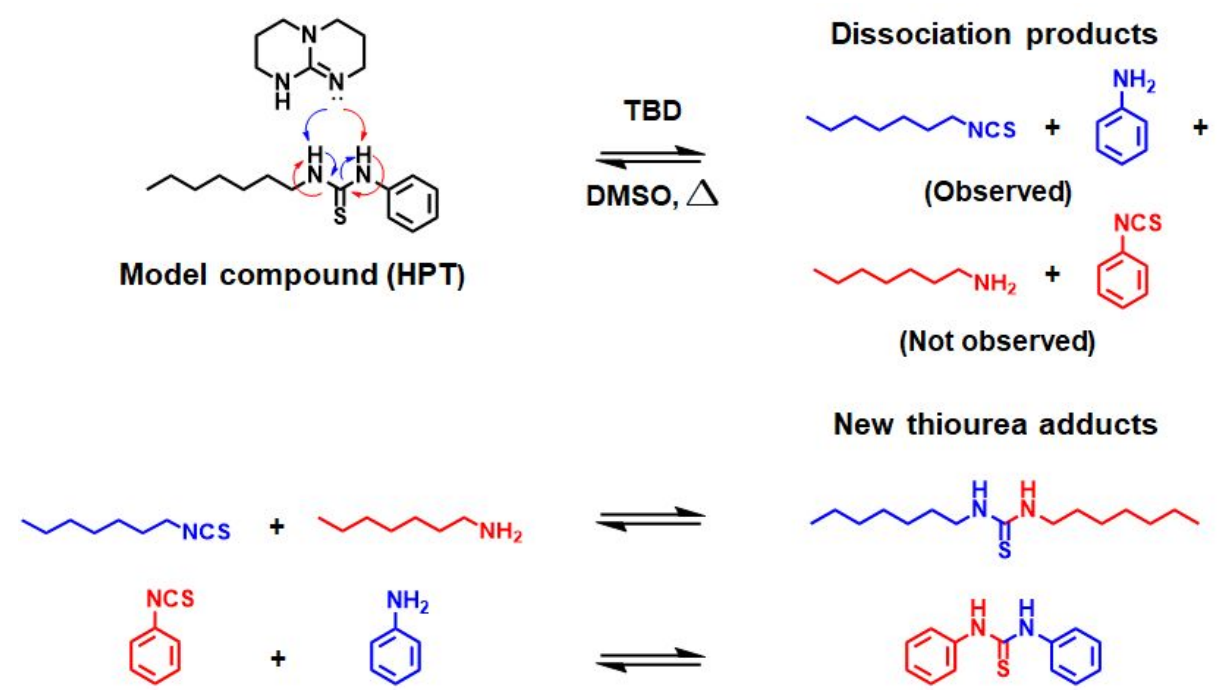

Figure S1o. A possible mechanism for the dynamic thiourea bond exchange reaction in the presence TBD catalyst. ${ }^{\left[S_{5}\right]}$ 


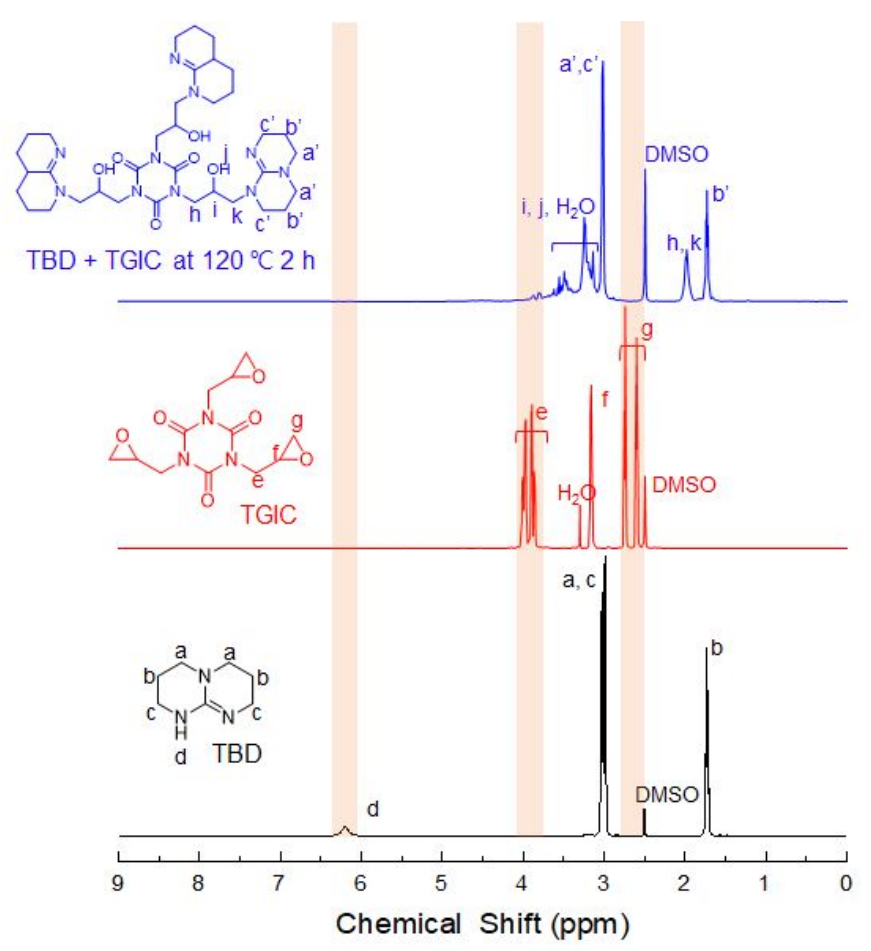

Figure S11. ${ }^{1} \mathrm{H}$ NMR spectra of TBD, TGIC, and TBD/TGIC mixture after reaction at $120{ }^{\circ} \mathrm{C}$ for $2 \mathrm{~h}$. A mixture of $0.504 \mathrm{mmol}$ TBD and $0.168 \mathrm{mmol}$ TGIC was fully dissolved in DMSO- $d_{6}(1 \mathrm{~mL})$ and the reaction was monitored by ${ }^{1} \mathrm{H}$ NMR.

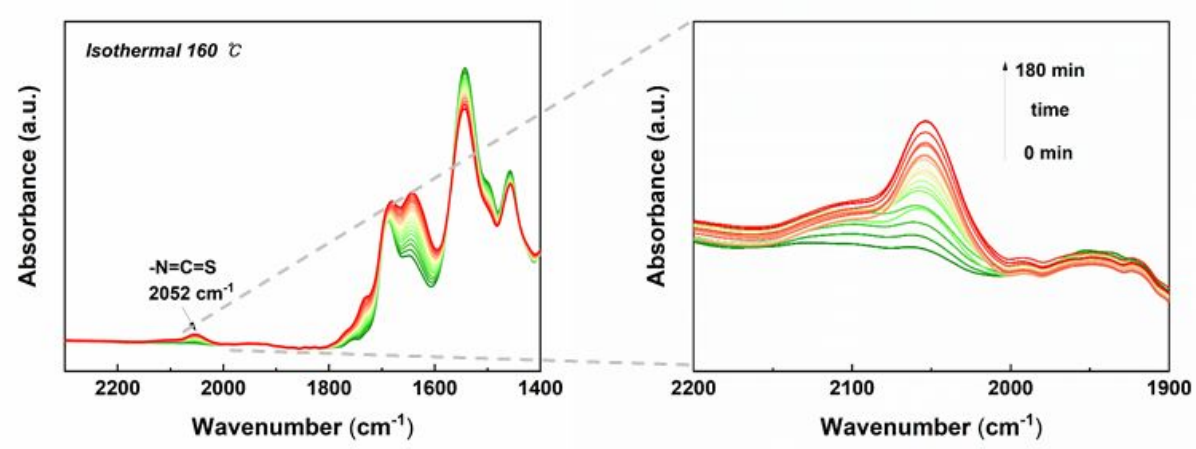

Figure S12. Real-time FT-IR spectra of BMPN8-3 upon heating at $160^{\circ} \mathrm{C}$. 


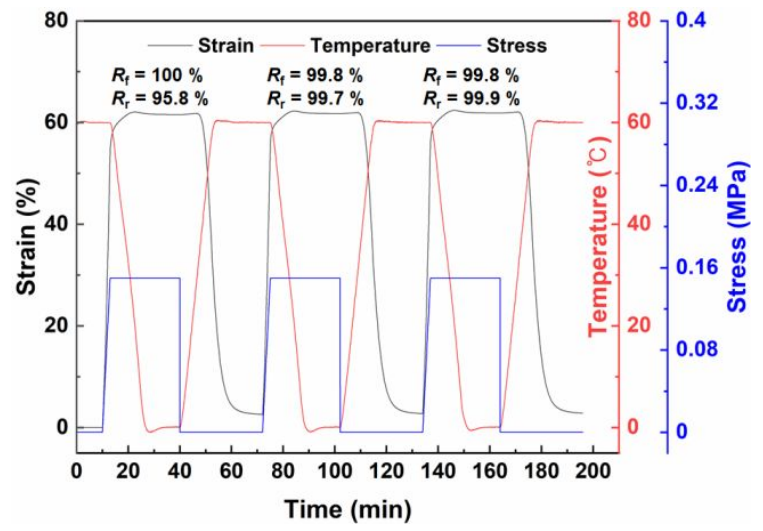

Figure S13. Quantitative shape memory cycles of BMPN8-3.

Permanent shapes (plasticity)

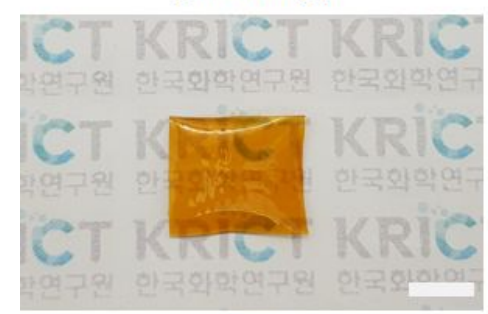

Rolling

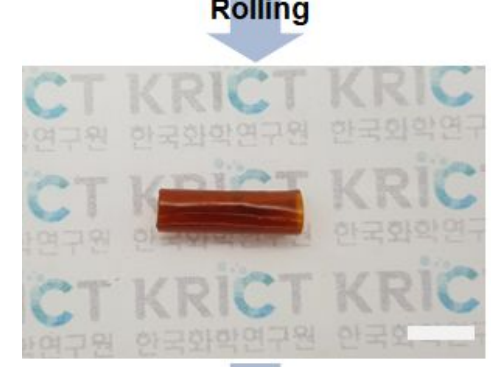

Twisting

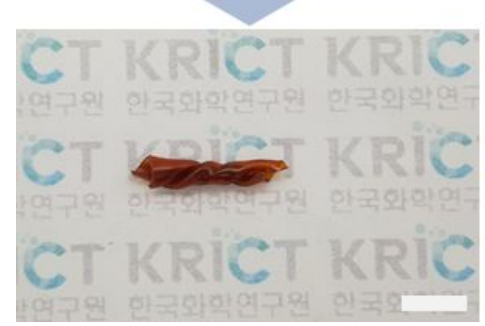

Temporary shapes

(elasticity)
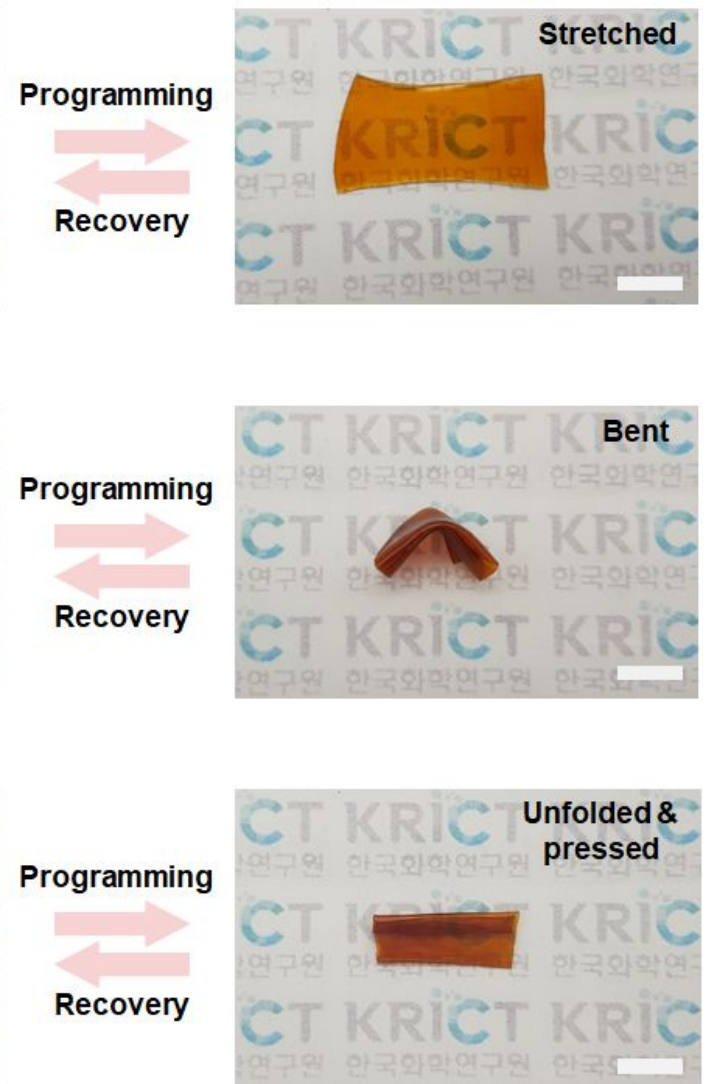

Figure S14. Complex shape manipulation of BMPN8-3 via plasticity-based cumulative shape reconfiguration and elasticity-based shape memory behaviors (scale bar $=1.5 \mathrm{~cm}$ ). 


\section{Mechanical Properties of BMPN8-3}
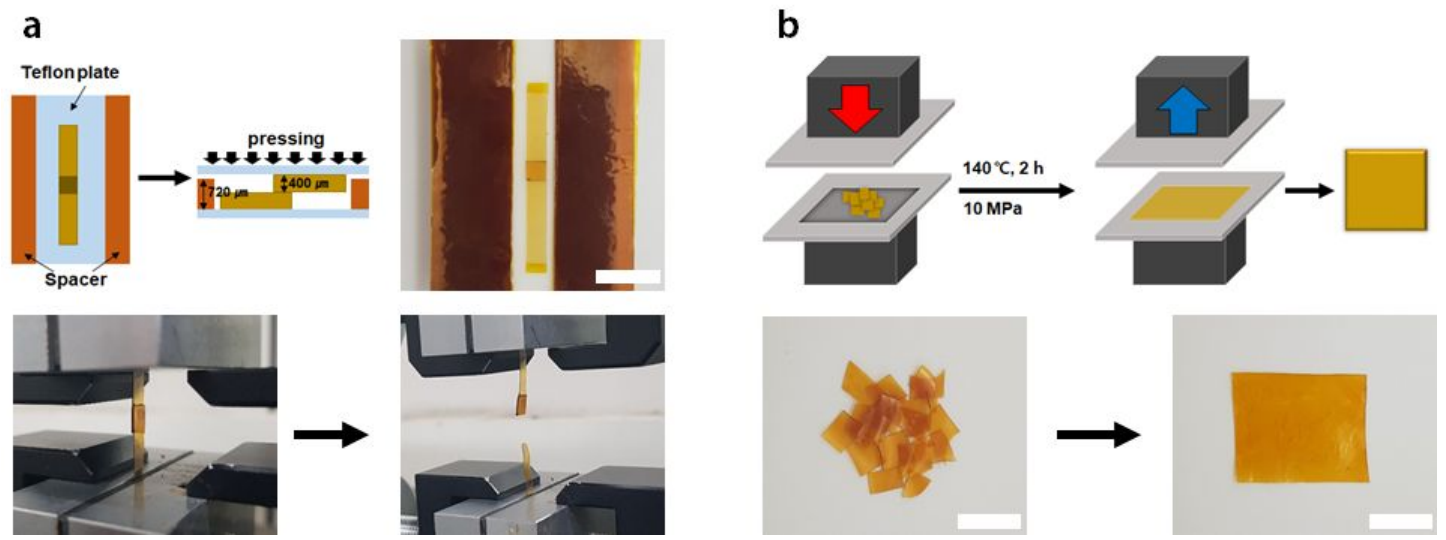

Figure S15. Schematic illustration and photographs of (a) thermal welding and (b) reprocessing procedures of BMPN8-3 (scale bar $=1.5 \mathrm{~cm}$ ).

Table S3. Summary of mechanical properties of pristine, welded, and reprocessed BMPN8-3

\begin{tabular}{lllll}
\hline Sample & $E^{a}(\mathrm{MPa})$ & $\sigma_{\mathrm{y}}{ }^{a}(\mathrm{MPa})$ & ${\varepsilon_{\mathrm{b}}}^{a}(\%)$ & $U_{\mathrm{T}^{a}}\left(\mathrm{MJ} \mathrm{m}^{-3}\right)$ \\
\hline BMPN8-3 $^{b}$ & $440 \pm 10$ & $23 \pm 1$ & $360 \pm 10$ & $71 \pm 9$ \\
w-BMPN8-3 $^{c}$ & $458 \pm 20$ & $19 \pm 0$ & $159 \pm 5$ & $22 \pm 0$ \\
r-BMPN8-3 $^{d}$ & $430 \pm 20$ & $19 \pm 0$ & $310 \pm 30$ & $52 \pm 4$ \\
\hline
\end{tabular}

${ }^{a}$ Determined from tensile testing at room temperature $\left(25 \pm 1{ }^{\circ} \mathrm{C}\right)$ and a strain rate of $0.011 \mathrm{~s}^{-1}$, where $E, \sigma_{\mathrm{y}}, \varepsilon_{\mathrm{b}}$, and $U_{\mathrm{T}}$ are elastic modulus, yield stress, strain at break, and toughness, respectively. ${ }^{b}$ Pristine BMPN8-3 film. ${ }^{c}$ Welded under $\approx 10 \%$ compression for $2 \mathrm{~h}$ at $160^{\circ} \mathrm{C}$. ${ }^{d}$ Reprocessed under $10 \mathrm{MPa}$ at $140{ }^{\circ} \mathrm{C}$ for $2 \mathrm{~h}$.

a
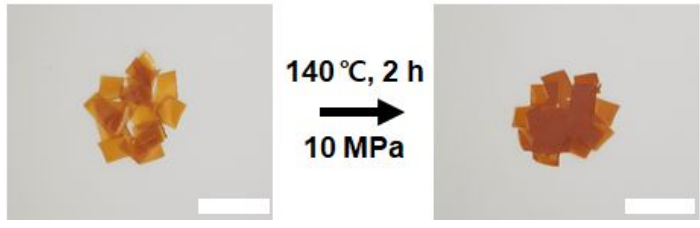

b

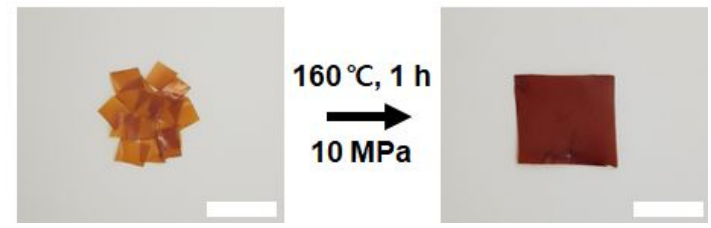

Figure S16. Photographs of reprocesed BMPN8 films under (a) 10 MPa at $140{ }^{\circ} \mathrm{C}$ for $2 \mathrm{~h}$ and (b) $10 \mathrm{MPa}$ at $160^{\circ} \mathrm{C}$ for $1 \mathrm{~h}$ (scale bar $=1.5 \mathrm{~cm}$ ). 
a

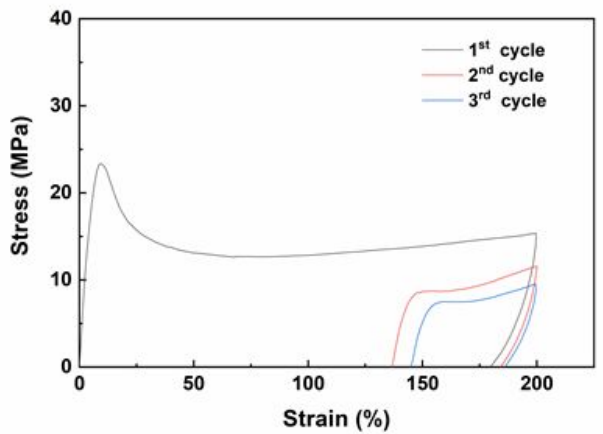

b

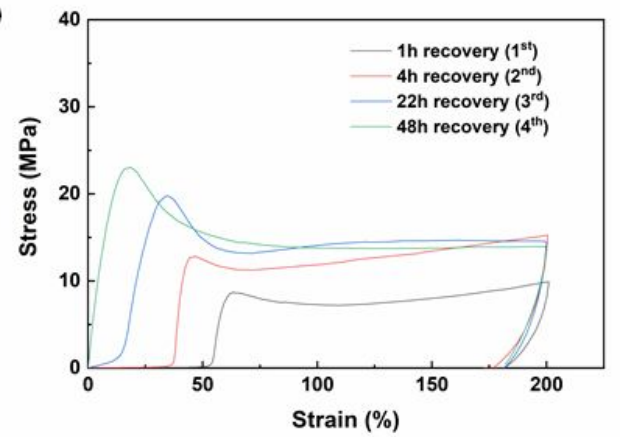

Figure S17. (a) Cyclic stress-strain curves of BMPN8-3 at room temperature $\left(25 \pm 1^{\circ} \mathrm{C}\right)$ and a strain rate of o.o11 s' ${ }^{-1}$ (b) Cyclic stress-strain curves of the pre-stretched BMPN8-3 (in (a)) after recovered for 1, 4, 22, $48 \mathrm{~h}$ at $25^{\circ} \mathrm{C}$.

Table S4. Summary on mechanical properties of biomimetic CANs with noncovalent sacrificial bonds and dynamic covalent bonds from recent literature reports

\begin{tabular}{|c|c|c|c|c|c|c|c|}
\hline Ref. & $\begin{array}{l}\text { Noncovalent } \\
\text { Sacrificial Bonds }\end{array}$ & $\begin{array}{l}\text { Dynamic } \\
\text { Covalent Bonds }\end{array}$ & $\begin{array}{l}E^{a} \\
(\mathrm{MPa})\end{array}$ & $\begin{array}{l}\sigma_{\mathrm{y}}^{a} \\
(\mathrm{MPa})\end{array}$ & $\begin{array}{l}\sigma_{\mathrm{u}}{ }^{a} \\
(\mathrm{MPa})\end{array}$ & $\begin{array}{l}\varepsilon_{\mathrm{b}}^{a} \\
(\%)\end{array}$ & Resilience $^{b}$ \\
\hline [S6] & H-bond & Disulfide Bond & - & $-e$ & 0.8 & 3,100 & 0 \\
\hline$\left[\mathrm{S}_{7}\right]$ & H-bond & Olefin Bond & 2.3 & $-e$ & 1.7 & 940 & O \\
\hline [S8] & H-bond & Ester Bond & $7 \cdot 1^{c}$ & $-e$ & 28 & 490 & O \\
\hline [S9] & $\begin{array}{l}\text { Metal-ligand } \\
\text { interaction }\end{array}$ & $\begin{array}{l}\text { Boronic Ester } \\
\text { Bond }\end{array}$ & $4.2^{d}$ & $-e$ & 26 & 420 & O \\
\hline$[\mathrm{S} 10]$ & $\begin{array}{l}\text { Metal-ligand } \\
\text { interaction }\end{array}$ & $\begin{array}{l}\text { Boronic Ester } \\
\text { Bond }\end{array}$ & $\approx 8$ & $-e$ & $\approx 11$ & $\approx 420$ & O \\
\hline$[\mathrm{S} 11]$ & H-bond & $\begin{array}{l}\text { Boronic Ester } \\
\text { Bond }\end{array}$ & $\approx 20$ & $-e$ & $\approx 6$ & $\approx 170$ & O \\
\hline$\left[\mathrm{S}_{12}\right]$ & $\begin{array}{l}\text { Metal-ligand } \\
\text { interactions }\end{array}$ & $\begin{array}{l}\text { Silyl Ether } \\
\text { Bond }\end{array}$ & $\approx 14^{c}$ & $-e$ & $\approx 20$ & $\approx 350$ & O \\
\hline $\begin{array}{l}\text { Present } \\
\text { Study }\end{array}$ & H-bond & Thiourea Bond & 440 & 23 & 19 & 360 & O \\
\hline
\end{tabular}

${ }^{a}$ Determined from tensile testing, where $E, \sigma_{\mathrm{y}}, \sigma_{\mathrm{u}}$, and $\varepsilon_{\mathrm{b}}$ are elastic modulus, yield stress, ultimate tensile stress, and strain at break, respectively. ${ }^{b}$ At room temperature. $\odot=$ complete recovery of shape and mechanical properties after deformation. ${ }^{c}$ Rubber modulus determined as the stress at $300 \%$ strain. ${ }^{d}$ Rubber modulus determined as the stress at $100 \%$ strain. ${ }^{e}$ Not observed. 


\section{References for Supporting Information}

[S1] Y. Yanagisawa, Y. Nan, K. Okuro and T. Aida, Science, 2018, 359, 72.

[S2] E. J. Cha, D. S. Lee, H. Kim, Y. H. Kim, B. G. Kim, Y. Yoo, Y. S. Kim and D-G. Kim, RSC $A d v$., 2019, 9, 15780 .

[S3] X. Wang and J. K. Gillham, J. Appl. Polym. Sci., 1991, 43, 2267.

[S4] A. R. de Luzuriaga, R. Martin, N. Markaide, A. Rekondo, G. Cabañero, J. Rodríguez and I. Odriozola, Mater. Horiz., 2016, 3, 241.

[S5] M. Vlatković and B. L. Feringa, Tetrahedron, 2019, 75, 2188.

[S6] R. Martin, A. Rekondo, A. R. de Luzuriaga, G. Cabãnero, H. J. Grande and I. Odriozola, J. Mater. Chem. A, 2014, 2, 5710.

[S7] J. A. Neal, D. Mozhdehi and Z. Guan, J. Am. Chem. Soc., 2015, 137, 4846.

[S8] Y. Liu, Z. Tang, S. Wu and B. Guo, ACS Macro Lett., 2019, 8, 193.

[S9] Y. Liu, Z. Tang, D. Wang, S. Wu and B. Guo, J. Mater. Chem. A, 2019, 7, 26867.

[S1o] Y. Chen, Z. Tang, Y. Liu, S. Wu and Baochun Guo, Macromolecules, 2019, 52, 3805.

[Si1] C. Zhang, Z. Yang, N. T. Duong, X. Li, Y. Nishiyama, Q. Wu, R. Zhang and P. Sun, Macromolecules, 2019, 52, 5014.

[S12] S. Wu, S. Fang, Z. Tang, F. Liu and B. Guo, Mater. Des. 2020, 192, 108756. 